\title{
Initial Insights on Land Adjudication in a Fit-for-Purpose Land Administration
}

\author{
Monica Lengoiboni ${ }^{1, *}$, Christine Richter ${ }^{2}$, Paul van Asperen ${ }^{3}$ and Jaap Zevenbergen ${ }^{1}$ (D) \\ 1 Faculty ITC, University of Twente, 7514 AE Enschede, The Netherlands; j.a.zevenbergen@utwente.nl \\ 2 Fraunhofer, 04109 Leipzig, Germany; christine.richter@imw.fraunhofer.de \\ 3 Rijkswaterstaat, 3500 GE Utrecht, The Netherlands; paul.van.asperen@rws.nl \\ * Correspondence: m.n.lengoiboni@utwente.nl
}

Citation: Lengoiboni, M.; Richter, C.; Asperen, P.v.; Zevenbergen, J. Initial Insights on Land Adjudication in a Fit-for-Purpose Land Administration. Land 2021, 10, 414. https://doi.org/ 10.3390/land10040414

Academic Editor: Robin McLaren

Received: 23 March 2021

Accepted: 9 April 2021

Published: 14 April 2021

Publisher's Note: MDPI stays neutral with regard to jurisdictional claims in published maps and institutional affiliations.

Copyright: (c) 2021 by the authors. Licensee MDPI, Basel, Switzerland. This article is an open access article distributed under the terms and conditions of the Creative Commons Attribution (CC BY) license (https:// creativecommons.org/licenses/by/ $4.0 /)$.

\begin{abstract}
Land adjudication constitute a series of sequential steps that if followed carefully and correctly, can lead to a sufficient determination of the varied interests in land including whether, and where they overlap, complement, conflict or compete with each other. This is a preliminary study aiming to find out how the adjudication process as it is conducted in the context of a fit-for-purpose land administration (FFPLA). A framework of components for adjudication in the FFPLA context is first developed. Further, the steps involved in accomplishing the adjudication components are compiled, assessed, and discussed from the perspective of the theory of collaborative governance. The study poses questions for consideration by implementers of land tenure documentation activities on how to identify the interests in land as they exist in their undocumented form. An understanding of the interaction between different types of interests in land in undocumented form as defined from the perspective of the communities themselves rather than from the law, could help assess which tenures and their attributes_can overlap or complement each other, or inform how they equate to specific rights in the legal perspective with minimal conflicts.
\end{abstract}

Keywords: community-based land adjudication; components of adjudication; fit-for-purpose land administration; land tenure; land rights

\section{Introduction}

In the formal land administration (LA), adjudication is a prerequisite for intentions to register land rights [1,2]. In itself land adjudication does not create rights, it only establishes existing rights [2-4]. Processes involved in the determination and definition of legal rights for registration must be understood because the rights become legally binding when registered [5]. Almost universally, however, legal frameworks guiding the adjudication process remain flawed because the determination of rights for registration is almost always restricted to land tenure that is based on individual/Western parcel-based statutory tenures and has been observed to have difficulties with catering for other forms of land tenure [6] This is because land rights in many countries are often complementary (e.g., when different parties share the same interest in the same land parcel), or overlapping (e.g., when several parties have different rights to the same parcel of land) [7]. A typical customary setting has a complex set of tenure arrangements/land rights, which may coexist and also seasonally shift [8]. In such a setting, private tenure forms can evolve over time in response to external pressures and as land gains value and as population grows [9]. Okoth-Ogendo and Van der Molen [3,4,6] observe that the adjudication process modifies tenure arrangements and that the 'traditional overlaps' are 'deleted' by individualized Western form of tenuresand thereby how land rights are organized. Interests conferred upon formal registration are often incompatible with how people use land in a customary tenure setting, which subsequently can lead to disputes and conflicts. Kabalamu [10] observes that despite international support and tenure reforms undertaken by successive governments in sub- 
Sahara Africa, inequalities, skewed distribution of land resources and land disputes and conflicts in form of disagreements and contestations over interests in land persist.

To embrace traditional overlaps in land tenure (hence the notion of 'inclusivity'), Okoth-Ogendo and Van der Molen [3,4,6] recognize that overlapping and complementary land rights could be preserved using an adjudication process that codifies the recognized rules within the customary tenure setting.

But how does the land adjudication process 'modify' or 'delete' overlapping or complementary rights, even though it is not supposed to alter existing rights? Laws can define land tenures-whether primary (hereon 'ownership rights') or secondary forms of land rights (hereon 'non-ownership rights'). In this study, 'ownership' is associated with the bundle of rights that give more, if not complete and exclusive control of a piece of land $[11,12]$ — while acknowledging that different countries/contexts may have different definitions or conceptualizations of what arrangements within the bundle of rights constitute full or less control of a piece of land. Non-ownership interests, in this study, refer to those associated with limited rights that do not amount to ownership. Non-ownership interests are often overlapping with ownership interests and as such, in this study, the non-ownership rights are the overlapping rights to land. Further, complementary rights can be in the form of ownership or non-ownership interests. Barrows and Roth [13] state that difficulties of sorting out and recording the complex set of land rights associated with an area (e.g., in a customary setting) resulted in the exclusion of certain right holders in practice. Those difficulties may pertain to the way in which framing the concept/idea of land rights is done during the adjudication process.

Ways in which stakeholders frame issues and the process of their interaction may explain collaborative success or failure [14]. According to Gray [14], frames refer to the lenses that stakeholders use to make sense of an issue or situation, and that the principal frames adapted by the stakeholders subsequently influence both the process and the outcomes. Besides difficulties in framing, a number of circumstances also lead to rightful claimants losing their land rights during the adjudication process. These include the people who are absent during the adjudication process, and when adjudication is conducted incorrectly, for example adjudication of land rights for pastoralists being at odds with their strategies of seasonal migrations based on their traditional land use patterns [15], and alterations into practices such as shifting cultivation and hunting and gathering. More recent studies show that such problems persist $[11,16,17]$. Therefore, the framing of land rights, as well as procedural factors during adjudication can influence the outcome of land rights registration.

New approaches for documenting land tenure have emerged in recent years, with emphasis on using participatory approaches for recording legal and social tenures using quick and affordable approaches understood as "pro-poor land administration" and "fitfor-purpose land administration" (FFPLA) [18-21]. Three core components of the FFPLA concept are the spatial, the legal and the institutional frameworks. The spatial framework is about adopting technologies and methodologies for collecting spatial data fast and affordably using general boundary approaches; the legal framework is about recognition of and recording social, legitimate, tenures as may exist in an area [21]; and the institutional framework concerns the governance aspect of land administration [18,19].

Non-governmental organizations (NGOs), international non-governmental organizations (INGOs), community-based organizations (CBOs) and others have emerged and collaborate with local communities in documenting tenure information using the FFPLA approach. In this sense the relevance of and need for a framework describing and clarifying the processes of adjudication in the context of a FFPLA is clear. So, what is needed for effective adjudication of both ownership and non-ownership tenure rights? Organizations facilitating community-based tenure documentation activities—knowingly or not—engage in some form of adjudication, where land rights are identified, mapped and documented. Unique is that collaborative approaches are employed, where different actors are brought together to collaborate in the adjudication process. Collaboration describes "a process 
through which parties who see different aspects of a problem can constructively explore their differences and search for solutions that go beyond their own limited vision of what is possible" [22]. Benefits of collaborative processes are a greater responsiveness and deliberations that can lead to effective, efficient and flexible solutions-often with a greater public acceptability [23].

It is unclear how the agencies facilitating a community-based adjudication activity capture social tenures. This paper reports on a preliminary study which aimed to (i) develop a framework for land adjudication in FFP land tenure documentation setting; (ii) gain insights into how the adjudication processes of those rights are being carried out in projects/programs designed to secure tenure; and (iii) develop initial ideas on how the concept of land tenure is framed (ownership and non-ownership) and how this influences what is eventually recorded. Factors that enable or hinder the framing or the adjudication process and their implications are discussed.

The paper is organized as follows: Section 2 presents the methodology, where a framework for land adjudication in a fit-for-purpose land tenure documentation is developed; Section 3 presents the results, where the processes of adjudication components-carried out in projects / programs designed to secure land tenure-are described; Section 4 builds on the results whereupon observations and questions for attention-in relation to the theory of collaborative governance-are raised by the researchers. This is followed by conclusions and recommendations. Recommendations are in the form of questions for future consideration by implementers of tenure documentation activities.

\section{Research Methodology}

This is an exploratory study focusing on the identification of adjudication components that yield to the documentation of both ownership and non-ownership tenure forms and land rights associated with them. An exploratory approach was preferred as it concerns the initial examination of an issue to gain insights and ideas about its underlying nature; or information gathering which can form the basis of an explanation for, or for immediate application to an administrative problem [24].

The study was undertaken in three phases: (i) establishing and defining the components of land adjudication; (ii) describing the processes used by the organizations to achieve these components; and (iii) gain insights on how land tenure and land rights are framed and how this influences the outcomes of what is eventually recorded.

Components of adjudication identified for this study serve as an initial analytical framework in order to summarize the findings from the questionnaire. As such, rather than an empirically fully substantiated theory for the case of FFPLA approaches, the frame provides entry points for understanding the interaction between different types of land tenures and land rights (e.g., when overlapping, complementing each other) as defined from the community perspective and as defined from perspective of statutory law and administrative procedure-depending on how this interaction plays out for each organization.

\subsection{Phase 1: Establishing and Defining the Components of Adjudication}

This part was guided by a review of two key documents: one, on the idea of adjudication in the context of formal land administration, and one, on the idea of adjudication in the context of FFPLA, which then led to the identification of a preliminary set of components of a community centered adjudication process.

Firstly, a set of components and their strategies-derived from the formal land administration context were identified. In the context of formal land administration, adjudication is anchored in the definition of Simpson [1], who is widely cited on the topic. The term adjudication is used for the "process by which all existing rights in any particular parcel or area of land are finally and authoritatively ascertained". According to Simpson [1], the purpose of adjudication is to establish finality on the existing land rights. Thus prior to the initial compilation of a register a legally defined procedure for official adjudication and le- 
gal registration of rights to land require three steps to be performed by formal adjudication committees. Step 1 identifies the persons and any qualification of his or her interests. This involves: (i) identification of owner (or holder of interests) and any qualification of his or her interest. Here, particulars of primary interests (comparable to "ownership" forms of tenures-in the context of this study) including the rights, restrictions and responsibilities (RRRs) attached to those tenures are identified; and (ii) identification of any particulars and claims to subordinate or derivative interests (comparable to "non-ownership" forms of tenures-in the context of this study) and persons attached to them so that relevant info is not overlooked. The name of the owner and particulars of any interest affecting the ownership must be ascertained at one and the same time; claims to ownership and claims to non-ownership interests must be considered together for anything relevant not to be overlooked [1]. Step 1 results in qualitative information about the land right holders. Step 2 identifies the boundaries and results in a map in three steps/strategies [1]: (i) demarcation, which is the physical marking of the area/parcel to be mapped; (ii) indication of the parcel by pointing out to the official concerned its position as demarcated by physical features or by visible monuments or, if it is invisible, where it lies; and (iii) survey of the boundaries and the preparation of a map or plan illustrating them. The order of how these steps can be followed is context dependent. Step 3 registers the rights in the land register and/or cadaster: a database of who-has-what-rights-where.

Secondly, a set of components and their strategies-derived from the FFPLA context were also identified. Here, the term adjudication is derived from the FFPLA guiding principles for country implementation [18]. These guidelines imply that the adjudication procedures are similar to the formal adjudication procedures i.e., identify, delineate, and survey the visible land parcel/area boundaries, and the rights determined are entered into a register [18]. In addition to formal land administration, the FFPLA places emphasis on (i) applying participatory adjudication methods to support the identification of tenures for documentation and (ii) monitoring and evaluation of tenure documentation activities [18,25]. According to Enemark et al. [18], participatory approaches to adjudication are expected to reveal a range of land parcels; all types of right holders (i.e., individuals, couples, households, etc.); and the relationships between land and people for documentation.

Thirdly, these components were combined to form the basic components of a framework for modelling the adjudication process in a FFPLA setting. By merging the key adjudication themes from the formal and FFPLA domains, the following emerged as fundamental items to inform the adjudication process:

\subsection{Phase 2: Describing the Processes Used by the Organizations to Achieve These Components}

After identifying the set of components of adjudication for a FFPLA setting, the next step was to assess the processes used to achieve these components in the real world. This study drew lessons from the organizations implementing tenure documentation activities in their various contexts. Criteria for selecting the organizations responding to this study are: (i) they are non-state actors e.g., NGOs, INGOs, CBOs or other; (ii) they support or conduct tenure documentation activities with communities; and (iii) they use participatory approaches when conducting land documentation activities. The organizations work in various countries and contexts. Two sets of documents were sent: (i) a background to the topic, and a need to gather the experiences on the practice of adjudication in the context of FFPLA; and (ii) a questionnaire, asking to provide systematic procedures or strategies used by them to achieve the components. The questionnaire was structured along the five components in Table 1 and were sent by email to the 11 organizations in January 2019. The questionnaire consisted of Likert statements formatted to scale $(1=$ never and 6 = always) and open-ended questions. Eight questionnaires were returned-mostly partially completed. For confidentiality reasons, identities of the responding organizations are not disclosed. 
Table 1. Essential components of a community-based adjudication process.

\begin{tabular}{ll}
\hline \multicolumn{1}{c}{ Component } & \multicolumn{1}{c}{ Is About } \\
\hline 1. Mobilization & Using participatory adjudication procedures, awareness creation \\
\hline 2. Adjudication of rights to land & Unpacking the varieties of interests to land (RRRs) and their right holders \\
\hline 3. Adjudication of boundaries & $\begin{array}{l}\text { Identification, delimitation, demarcation and mapping boundaries where land rights } \\
\text { begin/end. Unpacking the boundaries of varied types of land rights that exist in the area }\end{array}$ \\
\hline 4. Documentation & $\begin{array}{l}\text { Documentation of the adjudicated tenures and rights corresponding to those tenures and } \\
\text { their spatial areas in a cadastral database, including validation and dispute resolution }\end{array}$ \\
\hline 5. Monitoring & $\begin{array}{l}\text { Following up on the impacts of the documentation activities on tenures and their land } \\
\text { rights holders }\end{array}$ \\
\hline
\end{tabular}

\subsection{Analysis}

Results from the eight organizations responding to the questionnaires were synthesized. Content analysis was used to derive the categories of procedures used to accomplish each land adjudication component. The process of each adjudication component was addressed individually. The theory of collaborative governance was used as a benchmark for discussing the results. This theory describes the collaborations between public actors and non-state, semi-state or other state stakeholders, defined as "a process where one or more public agencies directly engage non-state, semi-state or other state stakeholders in a collective decision-making that is formal, consensus-oriented, and deliberative and that aims to make or implement new public policy or manage public programs or assets differently" [26]. In describing the kinds of power held by participants in collaborative processes, Purdy [27] reveals that power can be exercised structurally and relationally and suggests that "three arenas" of power come into play, which influence process design for collaboration: (i) participants arena: describes who is involved in a collaborative process and who leads it; (ii) process for collaboration arena: describes the where, when, and how of collaborative governance, influencing the nature of interaction and the modes that are used for communication and decision making; and (iii) content of collaboration arena: this describes the setting the agenda and establishing expectations regarding outcome of the process. Agreements in this phase will reflect in the outcomes, as the interpretations that people use to identify issues and understand alternatives are closely linked to the success of the process [14]. Framing the issue can result in stakeholders having different interpretations of the same issue and consequently, procedural factors-when acting on the issue-can explain outcomes [14]. In this study, the content arena is about how the topic of 'adjudicating land rights' or 'determining ownership rights' or 'determining non-ownership land rights'.

\section{Results: Processes Used to Accomplish the Adjudication Components in a FFPLA Setting}

Results presented here are based on the general strategies and experiences by the organizations when documenting tenure in a FFPLA approach. Processes within each land adjudication component are presented.

\subsection{Component: Mobilization Process}

This section describes the activities and experiences of the organizations during the mobilization process. Some of the countries where the organizations have conducted land tenure documentation activities (at the time of the interviews) include Africa (Burundi, Democratic Republic of Congo, Mozambique, Kenya, Nigeria, Uganda; Sudan, Namibia, Zambia, Benin, Gambia), South America (Bolivia, Colombia), and Asia (India, Iraq, Nepal, Philippines, Laos, Indonesia).

All organizations engage in community mobilization events prior to tenure documentation. The approaches used to convey information on tenure documentation activities to communities are diverse, including more standard approaches such as informing commu- 
nity leaders, holding community meetings and sharing of project promotional materials (written documents) such as flyers, banners, artistical drawings of the community delimitation process. Focus groups, theatre plays, on-the-job training and learning events are also a means to promote the tools and the participatory enumeration techniques, with the aim of getting feedback on applicability for the given context in the community. Moreover, approaches employing locally relevant media and means, including newspapers, radio and TV spots, quizzes, fairs on land tenure documentation and "door-to-door socializing" are also used, all the while attention is given to attendance and participation of women and vulnerable groups.

Various factors determine the number of community awareness sessions that can take place. These factors can be grouped into themes: (i) geographical factors, for example accessibility to target communities in remote rural areas; (ii) logistical factors, for example meetings are held via video in case pilot areas are located in very remote areas (iii), communal factors, for instance presence of different groups of the community at different times of the day, mechanisms to reach consensus in the community, absenteeism and composition of the community for participation process and (iv) interference of the process i.e., through internal or external factors. Sub processes as determining ownership and non-ownership interests and the mapping of ownership and non-ownership boundaries requires awareness creation. All organizations report that they always aim to understand the local ownership rights situation prior to the tenure documentation activities. There are those who lead the communities in the adjudication processes, as 'facilitators'. Six organizations responded to the questions on how the facilitators are selected, which follows two approaches: (i) in accordance with the law, where five organizations report government involvement in the adjudication process and (ii) through open recruitment, where community members are appointed as facilitators. All organizations always create awareness of the mapping process by training communities on approaches that enable them to indicate where the boundaries begin/end. Methods used to train on boundary mapping are diverse.

Regarding the role of technology developers in the mobilization, the study finds that they participate in community mobilization occasionally and in the case of two organizations very frequently.

Barriers to community mobilization can be categorized into the following types: logistical and infrastructural, for instance time limitations and transportation costs, barriers relating to the communities, for example community members' lack of understanding the benefits of tenure documentation, and cultural and political interferences, especially mistrust in the government, and dynamics of social exclusion, including gender biases.

To address these issues and reduce barriers, organizations focus on accommodating meeting places and times that are a best possible fit for the community in terms of work schedules, and using existing meetings, such as church meetings for the mobilization and awareness campaigns; and also, by directly supporting transport. Those who still cannot attend are notified in writing. Local coordinators or grassroot surveyors visit the homes of those who could not attend the meetings. In order to address barriers related to community's mistrust and fear the focus rests on spending sufficient time on socializing as the main goal of activities, to highlight the benefits of tenure documentation, and having multiple meetings to build trust and understanding.

Five organizations report positive results of addressing the barriers, in the sense that it contributed to a broadening of participation to more communities who are being involved in the documentation processes and more acceptance of the initiatives.

\subsection{Component: Adjudication of Interests in Land}

This section describes the organizations' activities and experiences on adjudication of both the ownership and non-ownership interests in land.

Most organizations train the facilitators and communities on the procedures for adjudicating and establishing the interests and their accompanying RRRs. Six organizations gave 
their methods on procedures, which follow one of three possible pathways: (i) establish the interests and RRRs during the actual practice of adjudication and rely on publication of results for communities to validate/verify the interests in land; (ii) begin by inquiring about the existing situation of land rights before embarking on any adjudication activities, sought from political, religious, and cultural leaders, existing documents on land ownership and tenure, including existing titles, and communities or neighbors themselves as witnesses and to verify interests in land; and (iii) a combination of the other two. In the case of missing formal administrative tenure records, a field survey may fill the gap.

Four sets of methods can be identified deployed by organizations to ensure a complete inventory of (non)-ownership interests in land: (i) baseline studies through means such as focus groups, interviews, key informant interviews and discussions with communities and community leaders; (ii) consultation meetings and workshops with community leaders, community members, government institutions; (iii) trainings given to both enumerators/facilitators and community members; and (iv) test runs and pilots, including the utilization of participatory mapping activities. Three organizations believe that nonownership rights are recorded, and other responses are more cautious on this.

All organizations indicate that some barriers exist that inhibit participating communities in adjudicating the ownership interests. Barriers include those related to: (i) community attributes i.e., conflicts at family level such us those linked to inheritance, men hijacking women's land rights, disputes with neighbors and conflicts at a larger level such as those arising between herders and farmers as well as due to ethnic division. Lack of knowledge and understanding on non-ownership rights and some community members partaking in "forum shopping" during adjudication activities are also in this category; (ii) attributes from the legality or legitimacy of interests in land such as unclear legal settings, bureaucracy and lack of capacity is mentioned as barriers, while lack of documentation on property lead to uncertainties on legitimacy of land rights; and (iii) attributes relating to mapping of boundaries-i.e., concerning the fuzziness and uncertainty of boundary locations.

Organizations use several approaches to address the barriers e.g., through training, lobbying, mediation, issuance of documents on land rights to right holders and using lessons from previous experiences in future planning. Resolution of barriers relating to community attributes have resulted to progress such as reduction in conflicts; willingness of communities to cooperate; better social inclusion of women and vulnerable groups.

\subsection{Component: Adjudication of Boundaries}

During the deployment of boundary mapping activities participating communities are able to indicate where boundaries begin/end. Communities can therefore map the boundaries relating to ownership interests. On non-ownership interests, seven organizations responded, with mixed responses on whether communities are able to map boundaries of non-ownership rights.

Categories of barriers to the mapping of boundaries relate to: (i) community attributes, including boundary disputes at family level, with neighbors, or two people claiming the same spatial unit, or a group of people disagreeing on the ownership of the same spatial unit are reported, but also ethnic divisions, violent conflicts, migration and displacement, encroachment of farming activities on pastoralist paths; (ii) legal attributes and/or questions of legitimacy of interests in land, including unclear legal settings, bureaucracy; lack of capacity, and that government does not recognize rights of poor, vulnerable and marginalized people and women; and (iii) the process of mapping of boundaries itself, for example difficulties in perceiving/conceptualizing non-ownership interests.

Organizations use several approaches to address the barriers e.g., through trainings, lobbying and mediation. Where needed, "Community development mechanisms" with the government as a stakeholder are established. Dialogues could lead to the "fair" relocation of people if necessary, for example through construction of settlements to protect the target population. On mediation, dedicated teams exist to handle cases and extents of gains and losses to parties involved are explained until an understanding is reached. Lobbying 
involves organizing multi-stakeholder meetings and awareness creation. Organizations mention that most of the conflicts are solved during the mediation process, which lead to 'better social environment' within the community members and also between the community and land administration. Increased participation during mapping activities creates consensus on the location of boundaries.

\subsection{Component: Documentation Process}

With the variety of interests in land, their accompanying RRRs and their boundaries determined, the next step is confirmation by documenting them. This part of the process is address in the following sub-sections.

The following types of interests are being recorded according to the respondents: (i) customary family based, (ii) customary clan based, (iii) occupancy, (iv) tenancy, including where the tenant owns crops but not the land (v) ownership, (vi) informal, (vii) possession, including rotating possession (viii) individual (freehold), leasehold, (ix) easements and rights of way: paths, roads, (x) state land, (xi) community lands allocated for specific purposes (e.g., churches, schools, sacred forests, community forest access), (xii) sacred places (in general) (xiii) conflict, (xiv), community lands reserved for future allocation, (xv) encumbrances, (xvi) pastoralist paths, (xvii) access to water, (xviii) use, (xix) extraction, (xx) community forest access, (xxi) storage places, (xxii) buffer along roads or other infrastructure as consequence of planning regulations Depending on country context, interests e.g., leaseholds can be categorized as ownership while in others as non-ownership. This contextualization blurs a strict distinction of 'ownership' and 'non-ownership' interests, making it difficult to generalize.

Upon documentation, the organizations report that they display tenure information for public view in the community, for example at community resource centres, village boards, or local leaders' offices; and/or at government offices at sub-county and local level, and, depending on context, at district level and in land administration agencies. The timeframe within which the objections and corrections can be voiced range between: 15-30 days; 45 days; 6 months (in accordance with the law) or is left open until the project closes. All organizations report that objections have been successfully addressed in the past.

Examples of barriers encountered that inhibit the documentation of ownership and non-ownership interests in the cadastral database relate to four attributes: (i) communities, e.g., social issues within the community or between communities or between a community and land administration agencies, (ii) legal, e.g., unclear legal settings and disagreements over the legitimacy of interests in land, (iii) the mapping process, e.g., difficulties to identify the boundaries and descriptions of RRRs and (iv) technical attributes of the process, e.g., minor omissions or additions done unintentionally by the field teams, this has potential to create confusion or conflict.

Trainings, lobbying and mediation are used to address the barriers. Training address technical issues including addressing unclear technical requirements/processes, while lobbying relates to awareness raising with political actors. Mediation is mentioned without further explanation. Meetings and workshops are also mentioned where examples of similar settings, region and topology are shared.

\subsection{Component: Monitoring Process}

Seven organizations responded to the questions on monitoring. About half the organizations return to the communities for monitoring. In terms of overall focus areas for evaluation two arenas can be distinguished: (i) those related to community impacts, including potential conflicts and level of community agreement, transactions and retrieval of documents, impact on communities in general and specifically what land interests have been overlooked (in most cases); and (ii), those elements relating to the process of documentation, including speed and quality of the process, the identification of challenges and adaptation, as well as maintenance of equipment. 
Two organizations reported that barriers to monitoring exist. Barriers relate to (i) community factors such as conflict, and (ii) the monitoring process, e.g., lack of skills and short-term given more importance over long-term monitoring. These barriers are addressed through multi-stakeholder meetings, lobbying with political actors, mediation, awareness raising, but also technical capacity building.

\section{Discussion}

The five components of a FFP adjudication process are addressed in this section. The theory of collaborative governance provides the analytical framework to discuss the results and raise questions for consideration about the results. Observations from the results are discussed against the theory of collaborative governance's three arenas of collaboration, whereupon the authors of this study raise questions for attention by implementers of tenure documentation activities. The three arenas are:

(i) participation arena (who is involved and who leads the process);

(ii) process for collaboration arena (where, when and how of collaborative process); and

(iii) content arena (setting the agenda and establishing expectations regarding the outcome of the process).

\subsection{Mobilization Process}

This phase emphasizes the use of participatory approaches in tenure documentation, thereby harnessing the potential for efficiency, inclusiveness, empowerment and sustainability [28-30].

(i) Participation arena: with a variety of state and no-state actors engaged, questions for consideration include:

- To what degree can the various stakeholders influence the perspective of, or how the concepts of land tenure and land rights are framed in the awareness raising session?

- Which participants have the authority to make decisions on the issue of land tenure and land rights to be recorded, and what are the consequences of this?

(ii) Process for collaboration arena: modes of communication during the mobilization phase were varied. Determinants of "where", "when", and "how" collaboration in the tenure documentation process are communicated in the community mobilization and awareness sessions through various means. Meanwhile, factors influencing the nature of interaction between the organizations and the communities are determined by a number of factors as listed in Section 3.1. Questions for consideration include:

- How do the various types of communications and interactions e.g., via TV, radio etc. influence participation in awareness raising sessions?

- What alternatives exist for community members who cannot be reached via TV, radio etc. to enable them to participate in tenure documentation processes?

- What are the consequences of community members being present and/or absent in the next phases of the tenure documentation processes?

- How do the various determinants of community awareness creation sessionsi.e., feedback, accessibility, community social structure, knowledge gap, distractions, logistics, budget or urgency - singly or combined-influence the subsequent phases of tenure documentation processes?

(iii) Content arena: setting the agenda of land tenure documentation may depend on the way in which the facilitators of adjudication activities frame the topic of land tenure adjudication, land rights determination and mapping to the communities during the mobilization phase. Communities may form their own interpretations of what they believe is expected of them during the tenure documentation process. It is worth noting that interests in land are different in nature and, depending on the perspective taken to identify and classify them, a number of key attributes (bundles of rights) make up a specific interest in land [31-33]. For every right an individual 
holds, rules exist that authorize what can or cannot be done with the right [32,33]. Hence land tenure is typically associated with a bundle of rights that define the conditions attached to them $[32,33]$. Bundles of rights therefore differ for different types of tenures, with "ownership" forms of tenure perceived as holding the complete bundle of rights over a particular resource compared to "non-ownership" forms of tenures [34].

It is important to consider the role of the developers of technologies for recording the tenure information. The processes of information sharing and translating between community and the technology developers, with emphasis on iterative feedback loops for the design of databases and applications in order to ensure that the technology reflects and allows for incorporation of land rights diversity. The questionnaire investigated to what extent the technology developers are informed about the local ownership and nonownership rights for inclusion in the data model. From the responses it appears that this is done, though not in all cases. Having feedback loops is reported less. This is a point of concern, because the community may check how, or if their land rights have been modelled according to the existing situation. It could also be a matter of design: where only the developer can set-up a model of land rights, or the system is made flexible to the extent that the facilitators or community themselves may design and implement their own data model.

Overall, the results here do not allow drawing generalized conclusions about the exact role played in the documentation of statutory legal vis-à-vis existing tenure and tenure rights. There are indications that statutory legal land rights over-write socially legitimate and locally specific, overlapping land rights. However, the questionnaire findings do not provide conclusive insights into the exact translation of rights according to local context into statutory frameworks. Also, the involvement of land administration officials in the process of land tenure identification indicates that land tenure becomes anchored in statutory and administrative legal foundations.

Of interest for this study is the idea of overlapping and complementary land rights. Two organizations reported the criteria being used to determine the existence of multiple types of rights on a parcel, or sorting out the different types of rights existing on a parcel: (i) baseline studies; and (ii) relying on community members to provide an overview of the rights.

The above approaches-singly or in combination-may reveal the types of land rights in an area, including whether they are overlapping or not. Subsequently, mapping using participatory, faster and affordable approaches serve to confirm the boundaries of the tenures.

Questions for consideration:

- How does the framing of the terms such as land adjudication, land rights, mapping etc. in the community awareness sessions reflect in subsequent processes (determination of land rights), and manifest as the types of land rights that are eventually recorded?

- In how far are the land rights from the community perspective translated to resemble a certain type of land right from the legal perspective, and subsequently, to which tenures will packaging of different bundles of land rights equate to?

- With just two out of eight organizations responding on the criteria for determining whether multiple types of rights exist, or for sorting out different types of rights existing on land, does this mean that most do indeed lack cues or criteria to categorize the variety of interests in land for documentation?

- What is the role of translation from one language to another (e.g., of terms such as land adjudication, land rights, mapping etc. and through the use of different terminologies in procedures, instructions, user interfaces, and on certificates) have on the outcome of the tenure documentation process?

\subsection{Adjudication Process-Adjudication of Land Rights}

A variety of interests in land have been identified as given in 3.1. How then, having principal frames around the identification of "interests in land" - adapted in the community 
mobilization phase-manifest in the implementation phase? Observations are drawn from the types of barriers inhibiting the determination of the land rights process, whose elements are hereby contextualized within the three arenas of collaborative theory:

(i) Participants arena: categories of participants in the mobilization phase will likely participate in the implementation phase as well, unless hindered by certain factors. According to Agarwal [28], participatory institutions/organizations operate on principles of cooperation but excluding members of the community can occur due to systemic factors-which in turn unfavorably affect both equity and institutional efficiency. Purdy [27] adds that as participation in a collaborative activity is often voluntary, it is biased towards those who have the resources to enable them to participate. On the other hand, beneficiaries of the land rights documentation project may also choose not to participate. Land rights holders' lack of participation due to various factors, as well as due to refusal to take part, is cited in this study as one of the obstacles during the identification of land rights activities. This has implications on the next phase. Questions for consideration:

- Depending on the proportion of beneficiaries participating, who determines the quorum for the community documentation process to proceed? And what alternatives exist for those absent?

- To what degree is the lack of participation due to systemic factors, voluntary decision rather than of circumstances that hinder participation, or lack of understanding-among other challenges listed as barriers in the identification of interests phase?

(ii) Process for collaboration: from the community perspective, those who were reached through the various modes of communication (during mobilization and implementation phases) are likely to be present during the rolling out of the adjudication of land rights and mapping activities. According to Ansell and Gash [26], "incentives to participate in collaborative governance will increase if stakeholders perceive achievement of their goals to be dependent on cooperating from other stakeholders", which requires stakeholders to build trust and interdependencies in working together towards achieving the goal. In the case of this study, where, when and how organizations leading the process convey the information, facilitate interactions and build trust with the communities can influence both the quality of the process and the outcomes of the documentation process. Questions for consideration:

- What proportion of anticipated beneficiaries of the tenure documentation activities are reached through the various modes of communication and how does this influence the tenure documentation process?

- What proportion of the anticipated beneficiaries of tenure documentation activities participate in the determination of land rights?

(iii) Content arena: an array of conceptions of forms of interests in land have been realized-as given in Section 3.4. Criteria for assessing and converting the communities' perspectives of land rights to their equivalent in the recorded or legal perspective did not feature in the results of this study. An understanding of the processes leading to differentiating the natures of, and classifying the types of traditional/community or informal land rights into their new forms e.g., "use", "extraction", "possession" or other in the recorded and legal context need to be further studied and understood. The questions that lead the adjudicators and communities to determine the types of land rights existing in an area, and then packaging the various land rights into their corresponding interest in the recorded or legal perspective are unclear. Content of the questions and methods that guide the unpacking and classifying of the different types of land rights from their undocumented form into the recorded or legal form, also taking into consideration the effects that language translation may have in the process need to be understood. Zevenbergen et al. [21] suggest the importance of ensuring that land documentation design lays a foundation for movement along the 
continuum of land rights, without having to jump out of one system (community perspectives of tenure and land rights) into another. As such, it is unclear how the baseline studies can determine and translate community land rights into those in Section 3.4. Further, criteria used to determine the existence of multiple land rights existing in a specific area and criteria for sorting out multiple types of land rights in order to determine that single or overlapping types of tenures exist also need to be understood. This would provide knowledge on how arrangements of bundles of rights in different types of interests in land enable them to coexist as "overlapping" in the same space. Questions for consideration:

- What criteria need to be framed and or adopted to ensure that communities comprehend the nature of and differences between overlapping and non-overlapping interests in land? Results, as is, suggest that community perspectives of land rights are in some cases being modified in the determination of land rights phase into some form of land rights in the legal context. The way in which this process is conducted did not feature in the results of this study, and this raises the question, what attributes, or sticks in the bundle of rights in the community perspective qualify to become a specific type of right in the legal context?

- Where interests are framed around the legal perspective, (e.g., freehold, leasehold, etc.) could this be a cascading effect arising from the lack of criteria that guide the notion of land tenure and land rights-from the perspective of the communities? And as such is this direct replacement with the de jure interests perhaps the easy way out of the complexities of describing interests in land from the perspective of the communities?

\subsection{Adjudication of Boundaries}

Sequentially, the identification of interests in land precedes the boundary mapping. The role of the boundaries therefore would be to confirm the limits within which those interests (already identified) in land apply. The identification of interests in land is therefore of fundamental importance for the preservation of traditional overlaps in land rights prior to the mapping. Equating adjudication of land rights to adjudication of boundaries can lead to individuals or groups of people losing their rights to land and this has been a longstanding discussion. For example, the original tenure reform statutes or laws in Kenya framed adjudication in customary areas around i.e., cultivation and residential occupation rights, and subsequently "the adjudication of land rights came to mean little more than the identification of homesteads plus the area of land to which household heads had cultivation rights" [3]. This resulted in "altering the structure of access to land in the family economy by vesting the attributes of ownership in adult male heads of households without at the same time giving adequate protection to the de facto or potential rights of women and children or others who had general access rights not accompanied by the power of ultimate control and further, the categories of land rights were unable to accommodate those who had other forms of rights in the adjudication area, nor describe land rights in those parts of the country where no permanent settlements nor cultivation existed e.g., in pastoralist areas" [3]. Coldham and Migot-Adholla et al. [15,35] observed that due to the problems involved in the adequate definition and protection of customary land tenure, land adjudication had the effect of depriving some people of their rights while conferring on others greater rights than they are entitled under customary law. Moreover, the "very narrow view on land rights in the statutes make it virtually impossible to bring to the adjudication register all the multiple rights claimable under customary tenures, and as such rightful claimants do lose their land rights as part of land adjudication" [36]. With the implementation of tenure documentation activities in the context of FFPLA, early indications highlight that the inclination towards recording single rather than the multiple types of tenures that may exist in an area persist [19,25].

Cutting across the three arenas of collaborative governance, questions for consideration include: 
- To what degree do the communities understand what is expected of them in terms of the adjudication process, and that the adjudication of land rights is different from the adjudication of boundaries?

- To what degree are the communities able to capture the boundaries of overlapping and non-overlapping interests in land?

\subsection{Documentation Process}

How have processes of identifying and mapping interests in land manifested in the documentation phase? Tenure types identified and mapped are subsequently forwarded to the documentation unit, where they are entered in the cadastral database. Thereafter a public display of the tenure information is placed to give room for objection or correction. Questions for consideration include:

(i) Participants arena: This phase may have implications on completeness in terms of representation on the types of interests in land recorded, and the right holders recorded. This is an important phase because the interests become legally binding once they are formally registered $[1,5,6]$, with potential for conflict when interests are misrepresented [10]. Public display of the tenure information therefore confirms the aim of the entire process and opens opportunities for objections and corrections. Omission and mistakes that appear during the public display of the outcomes could lead to frustrations and disputes. Questions for consideration:

- Whose interests in land are recorded? Whose is left out? Whose interest is altered?

- How to deal with future claims in case of omissions, or conflicts between community perspectives of land rights and the legal perspectives?

(ii) Observation on the process for collaboration arena and for content arena: In this study, it was mentioned that the process of documentation is not a problem as it is about confirming what has resulted from both the processes of mobilization and implementation of adjudication. For this reason, questions for consideration here are similar to those raised in the participants arena-under the documentation process.

(iii) Same as (ii) above.

\subsection{Monitoring}

Monitoring and evaluation focus in this study is specifically on which land interests are affected/overlooked by documentation and how documentation is conducted. It will be interesting to find out, in how far the nature as well as the extent of barriers to these processes (e.g., conflict, ethnic division) differ from barriers to the documentation process itself, where similar issues seem to play a role (e.g., mistrust, exclusionary trends in community). Results showed that barriers such as conflicts are addressed through training, lobbying and mediation-with positive outcomes. This confirms the view that conflict can actually create a powerful incentive for collaborative governance for conflict resolution [26]. Consensual approaches such as mediation try to find a harmony through intensive discussions and negotiations, during which all sides learn to understand the other party's concerns, conflict issues, fears and desires, with the aim to re-establish a positively functioning relationship. Also known as Alternative Dispute Resolution (ADR) approaches, they are cheaper and faster therefore often a preferable alternative to overloaded courts [37]. ADRs thus provide an avenue to deliver justice, a key element of the Sustainable Development Goal 16 [38].

The questionnaire for this study did not cover the process side and usability of system development, while this might contain challenges as well. First of all, the end user is not clearly defined yet. Is it the facilitator? Is it the youth from the community trained to capture the data? Or is it the community at large (do they capture the land rights and the boundaries themselves or does it relate to a system where every person can query the database and eventually transfer land or use other services provided)? In other words, the scope and the user group for each and every implementation may vary and may be given more attention in future research. 
Questions by the researchers regarding participants, process and content for collaboration arenas:

- How is the match between "community composition" before/during/after established?

- What means exist/can be developed to address structural challenges to longer term monitoring and evaluation, e.g., financial, political stability, migration/displacement?

- How to ensure consideration of and adjustment to discovering "the unexpected?"

- How do barriers and problems in evaluation and monitoring differ specifically from those encountered during documentation process itself?

- How to consider contextual complexity of environmental factors that influence outcomes at different points in time and over longer periods?

\section{Conclusions}

This study explores how ownership and non-ownership interests in land are being recorded in a FFPLA context-with a special focus on overlapping and complementary land rights. An exploratory research method was employed and results discussed against the theory of collaborative governance. Results from the eight organizations show that when discussing the topic of "adjudication of land rights", the legal perspective of land rights intersects with the perspective of communities regarding legitimate rights and interests in various ways during the documentation process. During adjudication of land rights alterations in the nature of land tenure and rights to legal forms may happen. Hence, the benefits as well as the limitations associated with the legal tenures, such as their exclusive nature are also introduced. As such, the study raised questions for consideration for future tenure documentation activities anchored on the three arenas of the collaborative governance theory i.e., the participation, process and content arenas. These questions may aid in consensus-oriented understandings on ownership rights, non-ownership rights and of course mapping and documentation of those land rights. Understanding complementarity and variability between interests in land in both the community and the legal perspectives will offer multiple lines or strategies for integration or conciliation when recording land interests. Without this understanding, opportunities for recording certain types of rights to land, including overlapping ones risk to fail also in the context of pro-poor land administration. Further, in the process of documenting the interests in land, future research and evaluation can look more carefully at the processes of information sharing and translation between community and technology developers, with emphasis on iterative feedback loops for the design of databases and applications.

This study offers preliminary insights to the questions posed at the outset. As mentioned in the methodology section, the components of adjudication identified serve as an initial analytical framework in order to summarize the findings from the questionnaire. As such, limitations of the study surround: (i) the many responses being contextual, which make it difficult to generalize; (ii) while results allow building a methodological skeleton for future inquiry, key themes and categories that emerged for each component can be used to fine-tune future questionnaires in future studies; and (iii) it may be possible that terminologies used in the questionnaire were interpreted differently by different respondents.

Author Contributions: Conceptualization, M.L., C.R., P.v.A.; methodology, M.L., C.R., P.v.A.; validation, M.L., C.R., P.v.A.; formal analysis, M.L., C.R., P.v.A.; investigation, M.L., C.R., P.v.A.; data curation, M.L., C.R., P.v.A.; writing-original draft preparation, M.L., C.R., P.v.A.; writing-review and editing, M.L., C.R., P.v.A., J.Z., funding acquisition, M.L. All authors have read and agreed to the published version of the manuscript.

Funding: This research was funded by the Dutch programme "Land Administration for National Development" (LAND) a partnership of the Ministry of Foreign Affairs and Kadaster, grant number 9002110. Funding of the publication costs for this article has kindly been provided by the School of Land Administration Studies, University of Twente, in combination with Kadaster International, The Netherlands. 
Institutional Review Board Statement: Not Applicable.

Informed Consent Statement: Not Applicable.

Data Availability Statement: Not Applicable.

Acknowledgments: Authors gratefully thank the organizations implementing participatory tenure documentation approaches for contributing to this study by providing data. Authors also acknowledge Christiaan Lemmen's invaluable support on editing the manuscript.

Conflicts of Interest: The authors declare no conflict of interest. The funders had no role in the design of the study; in the collection, analyses, or interpretation of data; in the writing of the manuscript, or in the decision to publish the results.

\section{References}

1. Simpson, S.R. Land Law and Registration; Cambridge University Press: Cambridge, UK, 1976.

2. Lawrance, J.D. Land adjudication. In Proceedings World Bank Seminar on LIS; World Bank: Washington, DC, USA, $1985 ;$ pp. 1-39.

3. Okoth-Ogendo, H.W.O. The Perils of Land Tenure Reform: The Case of Kenya; University of Nairobi: Nairobi, Kenya, 1986.

4. Van der Molen, P. The dynamic aspect of land administration: An often-forgotten component in system design. Comput. Environ. Urban Syst. 2002, 26, 361-381. [CrossRef]

5. Kaufmann, J.; Steudler, D. CADASTRE 2014-A Vision for a Future Cadastral System; International Federation of Surveyors: Copenhagen, Denmark, 1998.

6. Van der Molen, P. Future Cadastres. In Fair Land Governance: How to Legalise Land Rights for Rural Development; Otto, J.M., Hoekema, A., Eds.; Leiden University Press: Leiden, The Netherlands, 2012.

7. FAO. Land Tenure and Rural Development; FAO: Rome, Italy, 2002.

8. Tanner, C. Law Making in an African Context: The 1997 Mozambican Land Law; FAO Legal Papers Online 26; FAO: Rome, Italy, 2002.

9. Lipton, M. Land Reform in Developing Countries; Routledge: London, UK, 2009.

10. Kalabamu, F.T. Land tenure reforms and persistence of land conflicts in Sub-Saharan Africa-The case of Botswana. Land Use Policy 2019, 81, 337-345. [CrossRef]

11. Meinzen-Dick, R.; Mwangi, E. Cutting the web of interests: Pitfalls of formalizing property rights. Land Use Policy 2009, 26, 36-43. [CrossRef]

12. Davy, B. After form. The credibility thesis meets property theory. Land Use Policy 2018, 79, 854-862. [CrossRef]

13. Barrows, R.; Roth, M. Land Tenure and Investment in African Agriculture: Theory and Evidence. J. Mod. Afr. Stud. 1990, 28, 265-297. [CrossRef]

14. Gray, B. Strong opposition: Frame-based resistance to collaboration. J. Community Appl. Soc. Psychol. 2004, 14, 166-176. [CrossRef]

15. Coldham, S. The Effect of Registration of Title Upon Customary Land Rights in Kenya. J. Afr. Law 1978, 22, 91-111. [CrossRef]

16. Lengoiboni, M.; Bregt, A.K.; van der Molen, P. Pastoralism within land administration in Kenya-The missing link. Land Use Policy 2010, 27, 579-588. [CrossRef]

17. Broegaard, R.B.; Vongvisouk, T.; Mertz, O. Contradictory land use plans and policies in Laos: Tenure security and the threat of exclusion. World Dev. 2017, 89, 170-183. [CrossRef]

18. Enemark, S.; McLaren, R.; Lemmen, C. Fit-for-Purpose Land Administration Guiding Principles for Country Implementation; UN-793 Habitat/GLTN: Nairobi, Kenya, 2016.

19. Hendriks, B.; Zevenbergen, J.; Bennett, R.; Antonio, D. Pro-poor land administration: Towards practical, coordinated, and scalable recording systems for all. Land Use Policy 2019, 81, 21-38. [CrossRef]

20. Lengoiboni, M.; Richter, C.; Zevenbergen, J. Cross-cutting challenges to innovation in land tenure documentation. Land Use Policy 2019, 85, 21-32. [CrossRef]

21. Zevenbergen, J.; Augustinus, C.; Antonio, D.; Bennett, R. Pro-poor land administration: Principles for recording the land rights of the underrepresented. Land Use Policy 2013, 31, 595-604. [CrossRef]

22. Gray, B. Collaborating: Finding Common Ground for Multiparty Problems; Jossey-Bass: San Francisco, CA, USA, 1989.

23. Sousa, D.J.; Klyza, C.M. New directions in environmental policy making: An emerging collaborative regime or reinventing interest group liberalism. Nat. Resour. J. 2007, 47, 377.

24. McNabb, D.E. Research Methods for Political Science: Quantitative and Qualitative Methods; Routledge: London, UK, 2015.

25. Barry, M. Fit-for- purpose land administration-Administration that suits local circumstances or management bumper sticker? Surv. Rev. 2018, 50, 383-385. [CrossRef]

26. Ansell, C.; Gash, A. Collaborative Governance in Theory and Practice. J. Public Adm. Res. Theory 2008, 18, 543-571. [CrossRef]

27. Purdy, J.M. A framework for assessing power in collaborative governance processes. Public Adm. Rev. 2012, 72, 409-417. [CrossRef]

28. Agarwal, B. Participatory Exclusions, Community Forestry, and Gender: An Analysis for South Asia and a Conceptual Framework. World Dev. 2001, 29, 1623-1648. [CrossRef]

29. Uphoff, N. Fitting projects to people. Putting people first: Sociological variables in rural development; World Bank: Washington, DC, USA, 1985.

30. Knight, R.; Brinkhurst, M.; Vogelsang, J. Community Land Protection: Facilitators Guide; Namati: Washington, DC, USA, 2016. 
31. Bennett, R. Property Rights, Restrictions and Responsibilities: Their Nature, Design and Management. Ph.D. Thesis, The University of Melbourne, Melbourne, Australia, 2007. Available online: http://www.csdila.unimelb.edu.au/publication/thesis/ Rohan_Bennett_PhD_Thesis.pdf (accessed on 30 March 2021).

32. Bruce, J.W. Review of Tenure Terminology; Land Tenure Center, University of Wisconsin-Madison: Madison, WI, USA, 1998.

33. Schlager, E.; Ostrom, E. Property-rights regimes and natural resources: A conceptual analysis. Land Econ. 1992, 68, 249-262. [CrossRef]

34. Barry, D.; Meinzen-Dick, R. The invisible map: Community tenure rights. In Proceedings of the 12th Conference of the International Association for the Study of the Commons, (IASC), Cheltenham, UK, 14-18 July 2008.

35. Migot-Adholla, S.; Hazell, P.; Blarel, B.; Place, F. Indigenous land rights systems in sub-Saharan Africa: A constraint on productivity? World Bank Econ. Rev. 1991, 5, 155-175. [CrossRef]

36. Okoth-Ogendo, H.W.O. African Land Tenure Reform. In Agricultural Development in Kenya: An Economic Assessment; Oxford University Press: Nairobi, Kenya, 1976.

37. Wehrmann, B. Land Conflicts-A Practical Guide to Dealing with Land Disputes; GTZ: Eschborn, Germany, 2008.

38. UN General Assembly. Transforming Our World: The 2030 Agenda for Sustainable Development; Report No. A/RES/70/1; United Nations General Assembly: New York, NY, USA, 2015. 